\title{
Sarcopenia: Ammonia metabolism and hepatic encephalopathy
}

\author{
Ankur Jindal and Rakesh Kumar Jagdish \\ Department of Hepatology, Institute of Liver and Biliary Sciences, New Delhi, India
}

Sarcopenia (loss of muscle mass and/or strength) frequently complicates liver cirrhosis and adversely affects the quality of life; cirrhosis related liver decompensation and significantly decreases wait-list and post-liver transplantation survival. The main therapeutic strategies to improve or reverse sarcopenia include dietary interventions (supplemental calorie and protein intake), increased physical activity (supervised resistance and endurance exercises), hormonal therapy (testosterone), and ammonia lowering agents (L-ornithine L-aspartate, branch chain amino acids) as well as mechanistic approaches that target underlying molecular and metabolic abnormalities. Besides other factors, hyperammonemia has recently gained attention and increase sarcopenia by various mechanisms including increased expression of myostatin, increased phosphorylation of eukaryotic initiation factor 2a, cataplerosis of a ketoglutarate, mitochondrial dysfunction, increased reactive oxygen species that decrease protein synthesis and increased autophagy-mediated proteolysis. Sarcopenia contributes to frailty and increases the risk of minimal and overt hepatic encephalopathy. (Clin Mol Hepatol 2019;25:270-279)

Keywords: Sarcopenia; Hepatic encephalopathy; Liver cirrhosis; Ammonia; Testosterone

\section{SARCOPENIA CIRRHOSIS EPIDEMIOLOGY}

Sarcopenia includes loss of muscle mass and/or strength leading of physical derangements and frailty. ${ }^{1,2}$ Presence of cirrhosis is an important risk factor for the development of sarcopenia as a result of metabolic derangements caused by hepatocyte dysfunction. Sarcopenia is a major complication in cirrhosis and almost 50 to $70 \%$ of them develops sarcopenia. ${ }^{3}$ The prevalence rates are much higher in males (50-70\%) in comparison to female cirrhosis $(\leq 20 \%){ }^{4}$ The severity and prevalence of sarcopenia in cirrhosis correlate with Child-Pugh's grade. ${ }^{5}$ Sarcopenia when added to model for end-stage liver disease (MELD) score has improved the utility for predicting survival and is particularly useful in low MELD score patients (MELD below15). ${ }^{6,7}$

Sarcopenia contributes to fatigue, limits exercise tolerance and may have profound impact on performance status and activities of daily living. ${ }^{8}$ Prognostic significance of sarcopenia in decompensated cirrhosis is well reported. ${ }^{9.11}$ Major clinical consequences include higher wait-list mortality, poor quality of life (Table 1), higher morbidity and mortality after surgery in cirrhosis; and increased risk of infections ${ }^{13}$ and hepatic encephalopathy (HE). ${ }^{14}$ Moreover, sarcopenia itself may contribute to liver disease pro-

\footnotetext{
Abbreviations:

ATF4, activating transcription factor 4; ATP, adenosine triphosphate; a-KG, a ketoglutarate; BCAAs, branched-chain amino acids; elF2a, eukaryotic initiation factor 2; GABA, gamma-amino-n-butyric acid; GCN2, general control nonderepressible 2; HE, hepatic encephalopathy; HVPG, hepatic venous pressure gradient; IGF-1, insulin-like growth factor-1; ISR, integrated stress response; LOLA, L-ornithine L-aspartate; MELD, model for end-stage liver disease; mTOR, mammalian target of rapamycin; PAG, phosphate-activated enzyme glutaminase; TIPS, transjugular intrahepatic portosystemic shunt; TNF-a, tumor necrosis factor-alpha; UPP, ubiquitin-proteasome pathway
}

\section{Corresponding author : Ankur Jindal}

Department of Hepatology, Institute of Liver and Biliary Sciences, D1 Vasant Kunj, New Delhi 110070, India

Tel: +91-11-46300000, Fax: +91-11-26123504

E-mail: ankur.jindal3@gmail.com

https://orcid.org/0000-0001-5582-7759

Received : Jan. 30, 2019/ Accepted : Feb. 7, 2019

Copyright $\odot 2019$ by Korean Association for the Study of the Liver

This is an Open Access article distributed under the terms of the Creative Commons Attribution Non-Commercial License (http://creativecommons.org/licenses/by-nc/3.0/) which permits unrestricted non-commercial use, distribution, and reproduction in any medium, provided the original work is properly cited. 
Table 1. Prognostic scoring of sarcopenia in patients with liver cirrhosis in various studies

\begin{tabular}{lll}
\hline Score & \multicolumn{1}{c}{ Study } & \multicolumn{1}{c}{ Interpretation } \\
\hline Sarcopenia & Kim et al. ${ }^{5}$ (metanalysis) & Sarcopenia is a poor prognostic factor, independent of MELD and CTP scores \\
\hline MELD-sarcopenia score & Montano-Loza et al. $^{11}$ & $\begin{array}{c}\text { MELD-sarcopenia score, which combines MELD and psoas muscle area scores, is } \\
\text { superior to that of the MELD score }\end{array}$ \\
MELD $<15$ & Tandon et al. $^{4}$ & Impact of sarcopenia was significant in patients with low MELD scores < 15 \\
CTP A/B & Merli et al. ${ }^{14}$ & $\begin{array}{c}\text { Muscle loss was predictive of mortality in CTP class A and CTP class B patients but } \\
\text { not in patients with CTP class C cirrhosis }\end{array}$ \\
\hline
\end{tabular}

MELD, model for end-stage liver disease; CTP, Child Pugh's score.

gression, as a result, altered metabolism. Sarcopenia is also known to increase the length of intensive care unit and hospital stay after liver transplantation. ${ }^{15}$ Sarcopenia is one of the complications that does not reverse post-liver transplantation and may actually even worsen due to use of steroids and calcineurin inhibitors. ${ }^{16}$ Therefore it is critically important to identify strategies for improving muscle mass in advanced cirrhosis. Data from more recent trials have revealed that reversal of sarcopenia is associated with improved survival and lesser complications. ${ }^{4,17,18}$

Despite this, the understanding on the pathophysiology of sarcopenia is still limited and treatment options proposed are not well explored in large randomized controlled trials. This review summarizes the current understanding of etiological factors and pathophysiology of sarcopenia in cirrhosis; mechanism of hyperammonemia related sarcopenia and discuss current and novel treatment options and potential avenues for future research.

\section{CAUSES OF SARCOPENIA IN CIRRHOSIS}

Sarcopenia in liver disease is multifactorial. The reasons may be related to decreased nutrition intake, malabsorption, altered metabolism, hormonal factors, hyperammonemia, and increase muscle loss.

\section{Impaired nutrient intake and malabsorption}

Poor oral intake in common in patients with cirrhosis. ${ }^{19}$ This may be due to anorexia induced by elevated inflammatory cytokines; early satiety caused by raised intra-abdominal pressure due to ascites and altered taste due to dietary salt restrictions. ${ }^{20}$ Impaired intestinal motility and small intestinal bacterial overgrowth in cirrhosis contribute to nutrient malabsorption. ${ }^{21}$ Reduced bile flow in cirrhosis also contributes to fats and fat-soluble vitamins malabsorption. Pancreatic insufficiency in alcoholic related liver disease also contributes to steatorrhoea and fat malabsorption. ${ }^{22}$

\section{Altered metabolism}

Cirrhosis is a hypermetabolic state, with increasing demand for calories and protein. ${ }^{23}$ Hepatic glycogen stores are limited. Therefore, even after a short period of fasting, there is inappropriate excessive utilization of body fat and protein (from muscles) for gluconeogenesis. ${ }^{24}$ This state of accelerated starvation response in cirrhosis contributes to malnutrition and sarcopenia. Increased utilization of amino acids for gluconeogenesis in cirrhosis results in low plasma branched-chain amino acids (BCAAs) levels. ${ }^{25}$ Since BCAAs are the preferential energy source for skeletal muscles, low plasma BCAA may lead to muscle degradation. ${ }^{26}$

\section{Hormone deficiency}

More than $90 \%$ of advanced cirrhosis has low testosterone levels. ${ }^{27}$ Serum testosterone levels correlate with muscle mass in men. ${ }^{28}$ Testosterone improves muscle mass and increases protein synthesis by increasing levels of insulin-like growth factor-1 (IGF-1) and consequent mammalian target of rapamycin (mTOR) activation. Testosterone also inhibits myostatin production that leads to less inhibition of muscle satellite cell activity. ${ }^{29} \mathrm{~A}$ recent doubleblinded placebo controlled trial had demonstrated that male cirrhotics with low serum testosterone levels had marked improvement in muscle mass upon intramuscular testosterone therapy. ${ }^{30}$

\section{Increased muscle loss}

In cirrhosis, muscle proteolysis is stimulated through the activation of the ubiquitin-proteasome activity. As a result of chronic inflammation in cirrhosis, the pro-inflammatory cytokines such as tumor necrosis factor-alpha (TNF-a) and interleukin-1, 6 are markedly elevated, which in turn stimulate muscle autophagy. ${ }^{31}$ More- 
over, autophagy induced by alcohol use directly lead to sarcopenia in patients with alcoholic liver disease. ${ }^{32}$

\section{Impaired muscle growth}

Myostatin negatively regulates satellite cell proliferation and differentiation. Elevated myostatin levels contribute to sarcopenia in cirrhosis. ${ }^{33}$ Hyperammonemia has been recently shown to increase muscle myostatin expression via Toll-like receptor-independent nuclear factor kappa beta activation in an animal model. ${ }^{34}$ As serum and muscle ammonia levels are frequently elevated in cirrhosis due to impaired ureagenesis and portosystemic shunting, myostatin expression is significantly increased. The reduction in serum free testosterone levels, BCAA, and IGF-1 levels also lead to elevated myostatin levels in cirrhosis. ${ }^{35}$

\section{NORMAL SKELETAL MUSCLE REGULATION}

The mechanistic pathways influencing muscle mass and function in cirrhosis are directly controlled by regulatory factors affecting muscle protein synthesis, differentiation and proliferation of muscle satellite cells and muscle proteolysis. Besides these, during muscle wasting, quality of muscle is also affected.

\section{Muscle protein synthesis}

Physical exercise, leucine-enriched BCAAs, testosterone, insulin and IGF-1 upregulates protein kinase B leading to mTOR activation inside the muscle cell which in turn via activation of various intracellular pathways stimulates muscle protein synthesis. ${ }^{36}$

\section{Satellite cell differentiation and proliferation}

Myostatin, a negative regulator of satellite cells proliferation and differentiation ${ }^{37}$ maintain the activity of satellite cells in a quiescent state within the muscle. Ammonia in muscles stimulates myostatin thereby preventing muscle growth. ${ }^{38}$

\section{Muscle proteolysis}

Myostatin stimulates both ubiquitin-proteasome pathway (UPP) and autophagy. Hyperammonemia, inactivity and systemic inflammation also activate the UPP. ${ }^{32}$ However, a recent study demonstrated that UPP activity is unaltered but the autophagy pathway in muscle is increased during hyperammonemia. Deranged mitochondrial function and increase in reactive oxygen species generation also activate autophagy leading to sarcopenia.

\section{AMMONIA METABOLISM IN HEALTH AND LIVER CIRRHOSIS}

Enterocytes in small intestine through the production of ammonia from glutamine and colonic microflora through the catabolism of nitrogenous sources in the form of ingested protein and secreted urea play a significant role in generating ammonia that is transported to the liver via the portal circulation. ${ }^{39,40}$

The liver plays a major role in ammonia disposal. Periportal hepatocytes have enzymes required for urea cycle, which converts ammonia to urea to be removed by the kidney. Periportal hepatocytes also have phosphate-activated enzyme glutaminase (PAG) activity to generate glutamate needed for urea cycle. Conversely, peri-venous hepatocytes have abundant glutamine synthetase activity, which removes ammonia that has been bypassed from the periportal hepatocytes. Thus, ammonia level in blood is closely regulated by functional hepatic glutamine metabolism and urea cycle in liver. ${ }^{39,41}$

In skeletal muscle, despite low glutamine synthetase activity, the large whole-body skeletal muscle mass makes it possible to cause significant conversion of ammonia to glutamine. The kidneys excrete amount of glutamine produced; but excess glutamine may also enter enterocytes and again produce ammonia, continuing this vicious cycle. ${ }^{42}$ The activity of Intestinal PAG in the intestine is increased almost fourfold in cirrhotics in comparison to healthy individuals. ${ }^{43}$

Ammonia plays a major role in the pathogenesis of minimal and overt $\mathrm{HE}$ in cirrhosis. Besides HE, ammonia toxicity has also been shown to affect muscles and other organs. In advanced cirrhosis and portal hypertension, loss of functional hepatocytes and bypass of portal blood flow as a result of portal-systemic shunting significantly reduce the liver capacity to remove ammonia. In addition, increased renal ammonia production also contributes to hyperammonemia. ${ }^{44}$ Therefore, careful studies on alternative pathways of ammonia metabolism and clearance are warranted.

\section{HYPERAMMONEMIA AND MUSCLE}

In chronic liver disease, muscle plays a significant compensatory 
role in removing ammonia due to the presence of enzyme glutamine synthetase during the formation of glutamate to glutamine by NH3 (Fig. 1).

More recent studies by Dasarathy et al. have elegantly demonstrated that high serum and muscle ammonia level contribute to sarcopenia in cirrhosis. ${ }^{45}$ A vicious circle develops as a cirrhotic patient develops sarcopenia as NH3 clearance decreased in sarcopenic patients, which in turn leads to a higher risk of developing hyperammonemia and $\mathrm{HE}$.

\section{Ammonia mediates myostatin transcription and expression}

A previous study by Dasarathy ${ }^{45}$ had shown increased plasma levels and increased expression of myostatin in the skeletal muscle of cirrhotic patients. Upregulation of myostatin as a result of hyperammonemia is responsible for impaired proteostasis that contributes to sarcopenia. In the skeletal muscle, ammonia enters the muscle cell, by the Rh B glycoprotein class of ammonia transporters. Hyperammonemia leads to myostatin expression via an nuclear factor of kappa light polypeptide gene enhancer in B-cells (NF-kB)-dependent toll-like receptor independent pathway. Ammonia also inhibits mTOR directly through 5 '-adenosine monophosphate protein kinase dependent pathway. ${ }^{35}$ Qiu et al. recently demonstrated that exposure of mouse skeletal muscle myotubes in culture to ammonium acetate caused a time- and concentration-dependent increase in myostatin mRNA and protein expression. ${ }^{34}$ High concentrations of myostatin in serum were associated

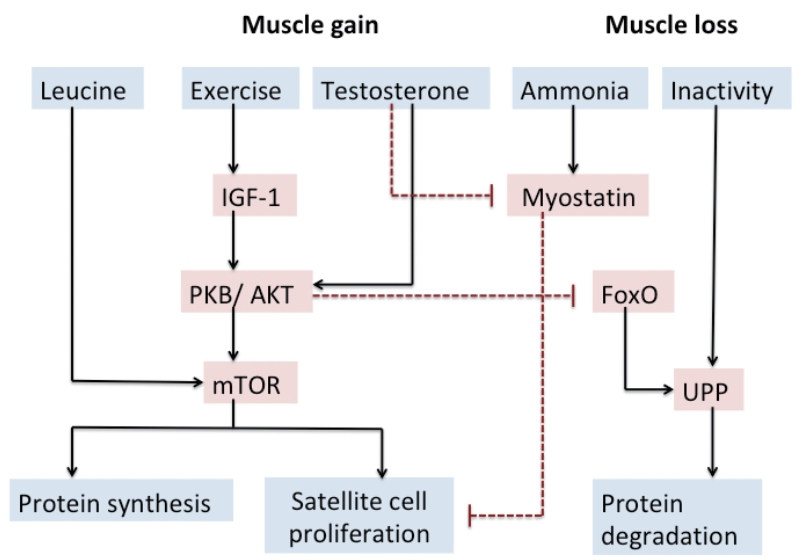

Figure 1. Muscle regulation and potential therapeutic strategies. Solid arrows indicate activating pathways. Dashed lines indicate inhibitory pathways. IGF-1, insulin-like growth factor 1; PKB/AKT, protein kinase B; mTOR, mammalian target of rapamycin; FoxO, forkhead box transcription factor; UPP, ubiquitin-proteasome pathway. with sarcopenia as measured by psoas muscle index on computed tomography, high serum ammonia concentration, low serum albumin, and severity of liver disease characterized by high Child-Pugh score. $^{46}$

\section{Ammonia mediates muscle autophagy}

Autophagy has been found to be increased in muscle in experimental models of cirrhosis or during hyperammonemia but ubiquitin-mediated proteolysis is not activated. ${ }^{47}$ Alternative possible mechanisms for activation of autophagy may include ammonia mediated mitochondrial dysfunction and generation of reactive oxygen species. ${ }^{48}$

\section{Ammonia-induced inhibition of muscle protein synthesis}

Ammonia causes activation of general control nonderepressible 2 (GCN2) kinase (amino acid deficiency sensor) which inactivate the eukaryotic initiation factor 2 (elF2a) and it also causes inactivation of mTORC1, resulting in global repression of mRNA translation and hence decrease in protein synthesis in the skeletal muscle. ${ }^{49}$ Under physiological conditions, phosphorylation of elF2a is followed by an adaptive integrated stress response (ISR) that is mediated via upregulation of activating transcription factor 4 (ATF4) which through downstream signaling pathways leads to the reversible dephosphorylation of phosphor-elF2a. ${ }^{50}$ The exact mechanisms and consequences of GCN2 activation during hyperammonemia and cirrhosis are not known but decreased in the plasma concentration of BCAA is a proposed mechanism of activation of GCN2.

In addition to the myostatin mediated signaling perturbations during hyperammonemia, In the mitochondria, ammonia is converted to glutamate by a ketoglutarate ( $\mathrm{a}-\mathrm{KG}$ ), a critical tricarboxylic acid (TCA) cycle intermediate, and it then subsequently help in conversion of glutamate to glutamine in the skeletal muscle that is then exchanged for leucine by SLC7A5. ${ }^{51,52}$ Both hyperammonemia and loss of a-KG contribute to the sarcopenia, both loss of muscle mass and impaired contractile function due to mitochondrial dysfunction and reduced adenosine triphosphate (ATP). ${ }^{53}$ Recent data also show post-translational modifications of proteins is responsible for impaired muscle strength and consequent frailty. ${ }^{54}$

However, in cirrhosis, skeletal muscle ammonia concentrations are much higher potentially favoring cataplerosis or loss of critical 
TCA cycle intermediate like $\mathrm{a}-\mathrm{KG}$. This results in a lower flux of the TCA cycle, impaired mitochondrial function and decreased ATP synthesis. ${ }^{55}$ Low ATP concentrations may also cause reduced protein synthesis by hampering translation initiation.

\section{AMMONIA AND HE}

Risk of hyperammonemia increases with an increase in loss of muscle mass along with liver dysfunction as muscle helps in NH3 disposal in multiple ways. Studies have shown that venous blood ammonia levels are higher with patients with sarcopenia. ${ }^{56}$ Since ammonia easily crosses the blood-brain barrier, neurotoxic levels of ammonia in brain astrocytes causes the development and/or persistence of $\mathrm{HE}^{57}$ Therefore prevalence of overt and covert $\mathrm{HE}$ is higher in patients with muscle depletion and decreased muscle strength. ${ }^{14}$ Sarcopenia and frailty are thus important predictors of HE and are often under-recognized comorbid conditions (Table 2). ${ }^{14,58-64}$

$\mathrm{NH} 3$ in the brain acts as an osmotic agent by forming glutamine from glutamate with the help of enzyme glutamine synthetase. ${ }^{65}$ It causes astrocyte cell swelling, which leads to cerebral edema, increases intracranial pressure, and the risk of brain herniation. ${ }^{66}$ Astrocyte dysfunction also implicated in an increase in activity of the gamma-amino-n-butyric acid (GABA) system resulting in a decrease of energy delivery to other neural cells and the subse- quent production of endogenous benzodiazepines. There are many other factors implicated in astrocyte swelling independently of hyperammonemia. These factors are benzodiazepines, hyponatremia, and inflammatory cytokines. ${ }^{67,68}$

\section{TREATMENT}

There is no effective therapy for sarcopenia in cirrhosis. Data on treatment options aimed at mechanistic pathways that lead to sarcopenia are limited (Fig. 2). The focus of treatment is to reduce the severity and frequency of sarcopenia in cirrhosis to reduce mortality and associated complications.

\section{Exercise}

Lack of physical exercise is linked with sarcopenia and poor clinical outcomes in cirrhotics; however, there is limited evidence that exercise can reverse sarcopenia in cirrhosis. ${ }^{69}$ Six to 12 weeks of monitored aerobic exercise training programmes have been shown to be associated with significant improvements in muscle mass, muscle strength, peak V02, aerobic endurance, quality of life and hepatic venous pressure gradient (HVPG) reduction. ${ }^{70}$ Supervised physical training also prevents worsening of sarcopenia.

Both resistance and cardiovascular training exercise programs

Table 2. The impact of sarcopenia and frailty on the risk of HE

\begin{tabular}{|c|c|c|c|c|}
\hline Study & Patient population & Diagnostic test & $\begin{array}{l}\text { Prevalence of } \\
\text { sarcopenia }\end{array}$ & Relation to HE \\
\hline Kalaitzakis et al. ${ }^{59}$ & 128 patients with cirrhosis & Anthropometry & $40 \%$ & $\begin{array}{l}\text { HE in } 46 \% \text { with malnutrition vs. } 27 \% \\
\text { without malnutrition }(P=0.03)\end{array}$ \\
\hline Huisman et al. ${ }^{60}$ & $\begin{array}{l}84 \text { patients with } \\
\text { cirrhosis }\end{array}$ & Jamar hand grip strength & $67 \%$ & $\begin{array}{l}\text { HE in } 29 \% \text { with malnutrition vs. } 0 \% \\
\text { without malnutrition }(P<0.01)\end{array}$ \\
\hline Meza-Junco et al. ${ }^{61}$ & $\begin{array}{l}116 \text { patients with HCC being } \\
\text { evaluated for } L T\end{array}$ & $\begin{array}{l}\text { Skeletal muscle mass at the } \\
\text { third lumbar spine }\end{array}$ & $35 \%$ & $\begin{array}{l}\text { HE in } 23 \% \text { with sarcopenia vs. } 12 \% \\
\text { without sarcopenia }(P=0.2)\end{array}$ \\
\hline Merli et al. ${ }^{14}$ & 300 patients with cirrhosis & Anthropometry & $48 \%$ & $\begin{array}{l}\text { Overt HE in } 30 \% \text { with sarcopenia vs. } 15 \% \\
\text { without sarcopenia ( } P=0.003 \text { ) } \\
\text { Minimal HE in } 49 \% \text { with sarcopenia vs. } \\
\text { 30\% without sarcopenia ( } P=0.001)\end{array}$ \\
\hline Montano-Loza et al. ${ }^{62}$ & $\begin{array}{l}248 \text { patients with cirrhosis } \\
\text { undergoing } L T\end{array}$ & 3rd lumbar spine area & $45 \%$ & $\begin{array}{l}\text { HE in } 60 \% \text { with sarcopenia vs. } 49 \% \\
\text { without sarcopenia }(P=0.10)\end{array}$ \\
\hline Verna et al. ${ }^{63}$ & $\begin{array}{l}82 \text { patients on the LT wait } \\
\text { list }\end{array}$ & Fried Frailty Instrument & $38 \%$ & $\begin{array}{l}\text { HE in } 65 \% \text { of frail patients vs. } 46 \% \text { who } \\
\text { were not frail }(P=0.10)\end{array}$ \\
\hline Lai et al. ${ }^{64}$ & $\begin{array}{l}294 \text { patients on the LT wait } \\
\text { list }\end{array}$ & Fried Frailty Instrument & $17 \%$ & $\begin{array}{l}\text { HE in } 26 \% \text { of frail patients vs. } 17 \% \text { who } \\
\text { were not frail }(P=0.17)\end{array}$ \\
\hline
\end{tabular}

HE, hepatic encephalopathy; HCC, hepatocellular carcinoma; LT, liver transplantation. 


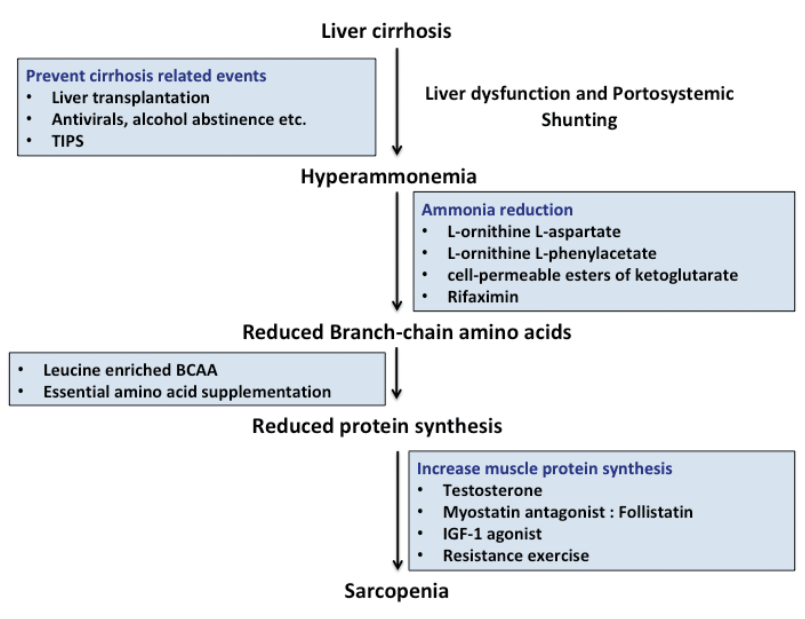

Figure 2. Overview of strategies to reverse sarcopenia in cirrhosis. The step-wise approach for management of sarcopenia are depicted. TIPS, transjugular intrahepatic portosystemic shunt; BCAA, branched-chain amino acid; IGF-1, insulin-like growth factor-1.

have shown benefit compared to placebo. ${ }^{71}$ Resistance exercises improve muscle mass. It promotes skeletal muscle regeneration by inducing muscle injury. ${ }^{72}$ Similarly, endurance exercises are important to improve functional capacity but have not been shown to do reverse sarcopenia. Future trials in sarcopenia in cirrhosis with a combination of resistance and endurance exercise may potentially improve muscle mass and strength. A study by Jones et al. have shown improvement in exercise capacity and muscle strength in response to exercise in cirrhotics. ${ }^{73}$ However, excessive exercise increases energy expenditure and may accelerate protein catabolism. It is advisable to recommend brisk walking at least 120 to 150 minutes per week, and lifting lightweights two to three times per week.

\section{Dietary interventions}

Nutritional management plays an important role in the management of $\mathrm{HE}$ and possibly sarcopenia and frailty. Key nutritional strategies include; small frequent meals by shortening the time interval between meals so as to increase total caloric and protein intake. This may lead to a decrease in gluconeogenesis and increase muscle mass and strength. Simply increasing caloric intake does not delay or prevent the development of sarcopenia in cirrhosis. ${ }^{74}$ Fat and protein catabolism is also reduced by nighttime snacks, it also prevents hyperammonemia and HE. ${ }^{75}$ Data of nutritional supplementation for reversal of sarcopenia is limited. Cirrhotics have high protein requirements for muscle protein synthe- sis and maintenance or restoration of muscle mass.

\section{Anti-ammonia measures}

Treatment strategies aimed at ammonia reduction are effective in the prevention and treatment of HE but data on improvement in muscle mass and whether lowering ammonia restores proteostasis is limited.

\section{BCAA}

BCAA levels are low in cirrhosis. BCAA is highly metabolized in muscles. Supplementation of leucine-enriched BCAA provides the substrate for energy production as BCAA can replenish a-KG, which is depleted during hyperammonemia, as a-KG is aminated to glutamate. BCAA is also capable for increasing muscle protein synthesis via activation of the mTOR pathway. ${ }^{76}$

A trial by Tsien et al. recently showed that administration of leucine-enriched BCAA in human muscle significantly reduced muscle autophagy and improved mTOR signaling that leads to increased muscle protein synthesis. ${ }^{26}$ After three months of daily supplementation of BCAAs mixture $(0.24 \mathrm{~g} / \mathrm{kg} ; 50 \%$ L-leucine, $25 \%$ isoleucine and $25 \%$ valine) in cirrhosis, they have reported reduction in blood ammonia levels and subsequent improvement in $\mathrm{HE}^{27}$ A recent Cochrane review also concluded that administration of BCAA improves overt $\mathrm{HE}^{77}$ however, whether BCAA therapy improves sarcopenia need to be specially assessed in a randomized trial.

\section{L-ornithine L-aspartate (LOLA)}

$A$ recent study by Kumar et al. demonstrated that ammonialowering therapy with LOLA given for 4 weeks in portocaval anastomosis rats significantly decreased plasma and muscle ammonia concentrations that lead to improved lean body mass, grip strength, skeletal muscle mass, and diameter compared to untreated portocaval anastomosis rats. ${ }^{78}$ Moreover, ammonia-lowering therapy reversed elevated increased myostatin expression and autophagy markers in skeletal muscles. Further studies on longerterm and/or alternative ammonia-disposal treatments like ornithine phenylacetate and cell-permeable esters of a-KG are needed to demonstrate complete normalization of muscle ammonia concentrations. $^{79}$

\section{Rifaximin}

Non-absorbable antibiotics like rifaximin lower ammonia concentration and therefore may negatively regulate myostatin ex- 
pression and may also release more BCAAs for use as an energy substrate for muscles. ${ }^{80}$

\section{Testosterone}

The effects of testosterone therapy in cirrhosis with respect to sarcopenia has not been evaluated extensively, ${ }^{81,82}$ however a recent trial by Sinclair et al. have demonstrated that testosterone therapy in cirrhotic men with low baseline testosterone levels is safe and it increases muscle mass, bone mineral mass and reduces total fat mass. ${ }^{30}$

\section{IGF-1 and myostatin blockers}

Follistatin, a myostatin antagonist, has been shown to improve skeletal muscle mass in animal studies. Follistatin treated portocaval anastomosis rats had significantly greater weight gain, gastrocnemius muscle size, and increased grip strength. ${ }^{83,84}$ IGF-1 increase muscle protein synthesis and is previously reported to improve nitrogen retention in cirrhotic rats as well as reduce myostatin and increase muscle mass. ${ }^{85}$

\section{Reversal of portal hypertension}

Transjugular intrahepatic portosystemic shunt (TIPS) placement reverses portal hypertension-related complications like ascites and variceal rebleeding. TIPS also have been suggested as a potential treatment for sarcopenia in cirrhosis. In a study of TIPS outcomes in cirrhosis, muscle mass improved post-TIPS in $\leq 70 \%$ of patients with a significantly reduced $12 \mathrm{~m}$ mortality. Mechanism of TIPSrelated reversal of sarcopenia includes the reduction in portal pressure, reduction in ascites leading to reduced metabolic rate, increased appetite, and improved nutrition. ${ }^{18}$ In a recent study by Nardelli et al., sarcopenia constitutes a strong and independent risk factor for the development of HE after TIPS placement. ${ }^{86}$ The mechanism for sarcopenia and HE post TIPS is likely related to reduce the capacity on the capacity of ammonia removal in presence of muscle wasting. Consequently, improvement in muscle mass and nutritional status before TIPS is warranted to decrease the incidence of HE.

\section{Liver transplantation}

Liver transplantation definitely reverses portal hypertension and hepatocyte functions but sarcopenia does not reverse and may actually worsen. ${ }^{19}$ All patients post-transplantation require immunosuppressive medications such as corticosteroids, calcineurin inhibitors, and mTOR inhibitors and these medications are known to adversely affect muscle mass. ${ }^{87}$ The reversibility of hyperammonemia induced signaling responses and impaired protein synthesis after liver transplantation is not known. Further longer-term follow-up studies are required to better answer this issue. ${ }^{88}$

\section{CONCLUSION}

Sarcopenia and frailty are frequent in cirrhosis and predict important clinical outcomes, including mortality. Hepatic clearance of ammonia is significantly decreased in cirrhosis due to impaired urea synthesis and portosystemic shunts that lead to significant dependence on skeletal muscle for ammonia detoxification. The molecular pathways and mechanisms for hyperammonemia-induced sarcopenia have been recently proposed. Preclinical studies targeting hyperammonemia lay the foundation for mechanistic treatment of sarcopenia in liver disease. Strategies to improve muscle mass in cirrhosis may improve or prevent HE.

\section{Authors' contribution}

AJ participated in concept design, writing and critical approval of manuscript. RKJ participated in writing the manuscript and preparing tables and figures.

All authors participated in writing and final approval of manuscript.

\section{Conflicts of Interest}

No financial conflict of interest.

\section{REFERENCES}

1. Cruz-Jentoft AJ, Baeyens JP, Bauer JM, Boirie Y, Cederholm T, Landi $F$, et al. Sarcopenia: European consensus on definition and diagnosis: report of the European working group on sarcopenia in older people. Age Ageing 2010;39:412-423.

2. Janssen I. Evolution of sarcopenia research. Appl Physiol Nutr Metab 2010;35:707-712

3. Montano-Loza AJ. Clinical relevance of sarcopenia in patients with cirrhosis. World J Gastroenterol 2014;20:8061-8071.

4. Tandon P, Ney M, Irwin I, Ma MM, Gramlich L, Bain VG, et al. Severe muscle depletion in patients on the liver transplant wait list: 
its prevalence and independent prognostic value. Liver Transpl 2012;18:1209-1216.

5. Kim G, Kang SH, Kim MY, Baik SK. Prognostic value of sarcopenia in patients with liver cirrhosis: a systematic review and meta-analysis. PLoS One 2017;12:e0186990.

6. Montano-Loza AJ, Duarte-Rojo A, Meza-Junco J, Baracos VE, Sawyer MB, Pang JX, et al. Inclusion of sarcopenia within MELD (MELDSarcopenia) and the prediction of mortality in patients with cirrhosis. Clin Transl Gastroenterol 2015;6:e102.

7. Kang SH, Jeong WK, Baik SK, Cha SH, Kim MY. Impact of sarcopenia on prognostic value of cirrhosis: going beyond the hepatic venous pressure gradient and MELD score. J Cachexia Sarcopenia Muscle 2018;9:860-870.

8. Musumeci G. Sarcopenia and exercise "The State of the Art". J Funct Morphol Kinesiol 2017;2:40.

9. Hanai T, Shiraki M, Nishimura K, Ohnishi S, Imai K, Suetsugu A, et al. Sarcopenia impairs prognosis of patients with liver cirrhosis. Nutrition 2015;31:193-199.

10. Durand F, Buyse S, Francoz C, Laouénan C, Bruno O, Belghiti J, et al. Prognostic value of muscle atrophy in cirrhosis using psoas muscle thickness on computed tomography. J Hepatol 2014;60:1151-1157.

11. Montano-Loza AJ, Meza-Junco J, Prado CM, Lieffers JR, Baracos VE, Bain VG, et al. Muscle wasting is associated with mortality in patients with cirrhosis. Clin Gastroenterol Hepatol 2012;10:166-173, 173.e1.

12. Marchesini G, Bianchi G, Amodio P, Salerno F, Merli M, Panella C, et al. Factors associated with poor health-related quality of life of patients with cirrhosis. Gastroenterology 2001;120:170-178.

13. Krell RW, Kaul DR, Martin AR, Englesbe MJ, Sonnenday CJ, Cai S, et al. Association between sarcopenia and the risk of serious infection among adults undergoing liver transplantation. Liver Transpl 2013;19:1396-1402.

14. Merli M, Giusto M, Lucidi C, Giannelli V, Pentassuglio I, Di Gregorio $V$, et al. Muscle depletion increases the risk of overt and minimal hepatic encephalopathy: results of a prospective study. Metab Brain Dis 2013;28:281-284.

15. DiMartini A, Cruz RJ Jr, Dew MA, Myaskovsky L, Goodpaster B, Fox $K$, et al. Muscle mass predicts outcomes following liver transplantation. Liver Transpl 2013;19:1172-1180.

16. Dasarathy S. Posttransplant sarcopenia: an underrecognized early consequence of liver transplantation. Dig Dis Sci 2013;58:31033111.

17. Tsien C, Shah SN, McCullough AJ, Dasarathy S. Reversal of sarcopenia predicts survival after a transjugular intrahepatic portosystemic stent. Eur J Gastroenterol Hepatol 2013;25:85-93.

18. Tsien C, Garber A, Narayanan A, Shah SN, Barnes D, Eghtesad B, et al. Post-liver transplantation sarcopenia in cirrhosis: a prospective evaluation. J Gastroenterol Hepatol 2014;29:1250-1257.
19. Hayashi F, Matsumoto Y, Momoki C, Yuikawa M, Okada G, Hamakawa $E$, et al. Physical inactivity and insufficient dietary intake are associated with the frequency of sarcopenia in patients with compensated viral liver cirrhosis. Hepatol Res 2013;43:1264-1275.

20. Madden AM, Bradbury W, Morgan MY. Taste perception in cirrhosis: its relationship to circulating micronutrients and food preferences. Hepatology 1997;26:40-48.

21. Romiti A, Merli M, Martorano M, Parrilli G, Martino F, Riggio O, et al. Malabsorption and nutritional abnormalities in patients with liver cirrhosis. Ital J Gastroenterol 1990;22:118-123.

22. Aoufi Rabih S, García Agudo R, Legaz Huidobro ML, Ynfante Ferrús M, González Carro P, Pérez Roldán F, et al. Exocrine pancreatic insufficiency and chronic pancreatitis in chronic alcoholic liver disease: coincidence or shared toxicity? Pancreas 2014;43:730-734.

23. Morrison WL, Bouchier IA, Gibson JN, Rennie MJ. Skeletal muscle and whole-body protein turnover in cirrhosis. Clin Sci (Lond) 1990;78:613-619.

24. Roubenoff R. Sarcopenia: effects on body composition and function. J Gerontol A Biol Sci Med Sci 2003;58:1012-1017.

25. Tajiri K, Shimizu Y. Branched-chain amino acids in liver diseases. World J Gastroenterol 2013;19:7620-7629.

26. Tsien C, Davuluri G, Singh D, Allawy A, Ten Have GA, Thapaliya S, et al. Metabolic and molecular responses to leucine-enriched branched chain amino acid supplementation in the skeletal muscle of alcoholic cirrhosis. Hepatology 2015;61:2018-2029.

27. Handelsman DJ, Strasser S, McDonald JA, Conway AJ, McCaughan GW. Hypothalamic-pituitary-testicular function in end-stage nonalcoholic liver disease before and after liver transplantation. Clin Endocrinol (Oxf) 1995;43:331-337.

28. Grossmann M, Hoermann R, Gani L, Chan I, Cheung A, Gow PJ, et al. Low testosterone levels as an independent predictor of mortality in men with chronic liver disease. Clin Endocrinol (Oxf) 2012;77:323328.

29. Orr R, Fiatarone Singh M. The anabolic androgenic steroid oxandrolone in the treatment of wasting and catabolic disorders: review of efficacy and safety. Drugs 2004;64:725-750.

30. Sinclair M, Grossmann M, Hoermann R, Angus PW, Gow PJ. Testosterone therapy increases muscle mass in men with cirrhosis and low testosterone: a randomized controlled trial. J Hepatol 2016;65:906913.

31. Beyer I, Mets T, Bautmans I. Chronic low-grade inflammation and age-related sarcopenia. Curr Opin Clin Nutr Metab Care 2012;15:1222.

32. Thapaliya S, Runkana A, McMullen MR, Nagy LE, McDonald C, Naga Prasad SV, et al. Alcohol-induced autophagy contributes to loss in skeletal muscle mass. Autophagy 2014;10:677-690.

33. García PS, Cabbabe A, Kambadur R, Nicholas G, Csete M. Briefreports: elevated myostatin levels in patients with liver disease: 
a potential contributor to skeletal muscle wasting. Anesth Analg 2010;111:707-709

34. Qiu J, Thapaliya S, Runkana A, Yang Y, Tsien C, Mohan ML, et al. Hyperammonemia in cirrhosis induces transcriptional regulation of myostatin by an NF-KB-mediated mechanism. Proc Natl Acad Sci U S A 2013;110:18162-18167.

35. Zietz B, Lock G, Plach B, Drobnik W, Grossmann J, Schölmerich J, et al. Dysfunction of the hypothalamic-pituitary- glandular axes and relation to Child-Pugh classification in male patients with alcoholic and virus-related cirrhosis. Eur J Gastroenterol Hepatol 2003;15:495501.

36. Drummond MJ, Dreyer HC, Fry CS, Glynn EL, Rasmussen BB. Nutritional and contractile regulation of human skeletal muscle protein synthesis and mTORC1 signaling. J Appl Physiol (1985) 2009;106:1374-1384.

37. Garikipati DK, Rodgers BD. Myostatin inhibits myosatellite cell proliferation and consequently activates differentiation: evidence for endocrine-regulated transcript processing. J Endocrinol 2012;215:177187.

38. Olde Damink SW, Jalan R, Dejong CH. Interorgan ammonia trafficking in liver disease. Metab Brain Dis 2009;24:169-181.

39. Richardson AJ, McKain N, Wallace RJ. Ammonia production by human faecal bacteria, and the enumeration, isolation and characterization of bacteria capable of growth on peptides and amino acids. BMC Microbiol 2013;13:6.

40. Davila AM, Blachier F, Gotteland M, Andriamihaja M, Benetti PH, Sanz $Y$, et al. Intestinal luminal nitrogen metabolism: role of the gut microbiota and consequences for the host. Pharmacol Res 2013;68:95-107.

41. Walker V. Ammonia metabolism and hyperammonemic disorders. Adv Clin Chem 2014:67:73-150.

42. Wright G, Noiret L, Olde Damink SW, Jalan R. Interorgan ammonia metabolism in liver failure: the basis of current and future therapies. Liver Int 2011;31:163-175.

43. Schnabl B. Linking intestinal homeostasis and liver disease. Curr Opin Gastroenterol 2013;29:264-270.

44. Weiner ID, Verlander JW. Recent advances in understanding renal ammonia metabolism and transport. Curr Opin Nephrol Hypertens 2016;25:436-443

45. Dasarathy S. Myostatin and beyond in cirrhosis: all roads lead to sarcopenia. J Cachexia Sarcopenia Muscle 2017;8:864-869.

46. Nishikawa $H$, Enomoto $H$, Ishii $A$, Iwata $Y$, Miyamoto $Y$, Ishii $N$, et al. Elevated serum myostatin level is associated with worse survival in patients with liver cirrhosis. J Cachexia Sarcopenia Muscle 2017:8:915-925

47. Qiu J, Tsien C, Thapalaya S, Narayanan A, Weihl CC, Ching JK, et al. Hyperammonemia-mediated autophagy in skeletal muscle contributes to sarcopenia of cirrhosis. Am J Physiol Endocrinol Metab

\section{2;303:E983-E993.}

48. Kosenko E, Venediktova N, Kaminsky Y, Montoliu C, Felipo V. Sources of oxygen radicals in brain in acute ammonia intoxication in vivo. Brain Res 2003:981:193-200.

49. Davuluri G, Krokowski D, Guan BJ, Kumar A, Thapaliya S, Singh D, et al. Metabolic adaptation of skeletal muscle to hyperammonemia drives the beneficial effects of L-leucine in cirrhosis. J Hepato 2016;65:929-937.

50. Pakos-Zebrucka K, Koryga I, Mnich K, Ljujic M, Samali A, Gorman AM. The integrated stress response. EMBO Rep 2016;17:1374-1395.

51. Davuluri G, Allawy A, Thapaliya S, Rennison JH, Singh D, Kumar A, et al. Hyperammonaemia-induced skeletal muscle mitochondrial dysfunction results in cataplerosis and oxidative stress. J Physiol 2016:594:7341-7360.

52. Holeček M. Branched-chain amino acid supplementation in treatment of liver cirrhosis: updated views on how to attenuate their harmful effects on cataplerosis and ammonia formation. Nutrition 2017;41:80-85

53. Owen OE, Kalhan SC, Hanson RW. The key role of anaplerosis and cataplerosis for citric acid cycle function. J Biol Chem 2002;277:30409-30412.

54. McDaniel J, Davuluri G, Hill EA, Moyer M, Runkana A, Prayson R, et al. Hyperammonemia results in reduced muscle function independent of muscle mass. Am J Physiol Gastrointest Liver Physio 2016:310:G163-G170.

55. Jacobsen EB, Hamberg O, Quistorff B, Ott P. Reduced mitochondrial adenosine triphosphate synthesis in skeletal muscle in patients with Child-Pugh class B and C cirrhosis. Hepatology 2001;34:7-12.

56. Poh Z, Chang PE. A current review of the diagnostic and treatment strategies of hepatic encephalopathy. Int J Hepatol 2012;2012:480309.

57. Häussinger D, Schliess F. Pathogenetic mechanisms of hepatic encephalopathy. Gut 2008;57:1156-1165.

58. Lucero C, Verna EC. The role of sarcopenia and frailty in hepatic encephalopathy management. Clin Liver Dis 2015;19:507-528.

59. Kalaitzakis $E$, Olsson R, Henfridsson P, Hugosson I, Bengtsson M, Jalan $R$, et al. Malnutrition and diabetes mellitus are related to hepatic encephalopathy in patients with liver cirrhosis. Liver Int 2007;27:1194-1201.

60. Huisman EJ, Trip EJ, Siersema PD, van Hoek B, van Erpecum KJ. Protein energy malnutrition predicts complications in liver cirrhosis. Eur J Gastroenterol Hepatol 2011;23:982-989.

61. Meza-Junco J, Montano-Loza AJ, Baracos VE, Prado CM, Bain VG, Beaumont $C$, et al. Sarcopenia as a prognostic index of nutritional status in concurrent cirrhosis and hepatocellular carcinoma. J Clin Gastroenterol 2013:47:861-870.

62. Montano-Loza AJ, Meza-Junco J, Baracos VE, Prado CM, Ma M, Meeberg G, et al. Severe muscle depletion predicts postoperative length of stay but is not associated with survival after liver trans- 
plantation. Liver Transpl 2014;20:640-648.

63. Verna E, Chan C, Pisa J, Abdelmessih R, Lukose T, Krishnamoorthy $S$, et al. Frailty, physical performance, and sarcopenia measures in patients awaiting liver transplantation predict mortality and postoperative complications. Am J Transplant 2014;14(Suppl 3):742.

64. Lai JC, Feng S, Terrault NA, Lizaola B, Hayssen H, Covinsky K. Frailty predicts waitlist mortality in liver transplant candidates. Am J Transplant 2014;14:1870-1879.

65. Brusilow SW. Hyperammonemic encephalopathy. Medicine (Baltimore) 2002;81:240-249.

66. Häussinger D, Kircheis G, Fischer R, Schliess F, vom Dahl S. Hepatic encephalopathy in chronic liver disease: a clinical manifestation of astrocyte swelling and low-grade cerebral edema? J Hepatol 2000:32:1035-1038.

67. Guevara M, Baccaro ME, Torre A, Gómez-Ansón B, Ríos J, Torres $F$, et al. Hyponatremia is a risk factor of hepatic encephalopathy in patients with cirrhosis: a prospective study with time-dependent analysis. Am J Gastroenterol 2009;104:1382-1389.

68. Seyan AS, Hughes RD, Shawcross DL. Changing face of hepatic encephalopathy: role of inflammation and oxidative stress. World J Gastroenterol 2010;16:3347-3357.

69. Toshikuni N, Arisawa T, Tsutsumi M. Nutrition and exercise in the management of liver cirrhosis. World J Gastroenterol 2014;20:72867297.

70. Tandon P, Ismond KP, Riess K, Duarte-Rojo A, Al-Judaibi B, Dunn $M A$, et al. Exercise in cirrhosis: translating evidence and experience to practice. J Hepatol 2018;69:1164-1177.

71. Fyfe JJ, Bishop DJ, Stepto NK. Interference between concurrent resistance and endurance exercise: molecular bases and the role of individual training variables. Sports Med 2014;44:743-762.

72. Damas F, Phillips S, Vechin FC, Ugrinowitsch C. A review of resistance training-induced changes in skeletal muscle protein synthesis and their contribution to hypertrophy. Sports Med 2015;45:801-807.

73. Jones JC, Coombes JS, Macdonald GA. Exercise capacity and muscle strength in patients with cirrhosis. Liver Transpl 2012;18:146-151.

74. Campillo B, Bories PN, Pornin B, Devanlay M. Influence of liver failure, ascites, and energy expenditure on the response to oral nutrition in alcoholic liver cirrhosis. Nutrition 1997;13:613-621.

75. Okuda H, Shiratori K. Long-term nutritional assessment and quality of life in patients with cirrhosis taking a late evening snack. J Gastroenterol 2007;42:186-187.

76. Matsumura T, Morinaga Y, Fujitani S, Takehana K, Nishitani S, Son- aka I. Oral administration of branched-chain amino acids activates the mTOR signal in cirrhotic rat liver. Hepatol Res 2005;33:27-32.

77. Gluud LL, Dam G, Les I, Córdoba J, Marchesini G, Borre M, et al. Branched-chain amino acids for people with hepatic encephalopathy. Cochrane Database Syst Rev 2015;(9):CD001939.

78. Kumar A, Davuluri G, Silva RNE, Engelen MPKJ, Ten Have GAM, Prayson $R$, et al. Ammonia lowering reverses sarcopenia of cirrhosis by restoring skeletal muscle proteostasis. Hepatology 2017;65:20452058.

79. Balasubramaniyan V, Wright G, Sharma V, Davies NA, Sharifi Y, Habtesion $A$, et al. Ammonia reduction with ornithine phenylacetate restores brain eNOS activity via the DDAH-ADMA pathway in bile duct-ligated cirrhotic rats. Am J Physiol Gastrointest Liver Physiol 2012;302:G145-G152.

80. Rose CF. Ammonia-lowering strategies for the treatment of hepatic encephalopathy. Clin Pharmacol Ther 2012;92:321-331.

81. Young NR, Baker HW, Liu G, Seeman E. Body composition and muscle strength in healthy men receiving testosterone enanthate for contraception. J Clin Endocrinol Metab 1993;77:1028-1032.

82. Schlevogt B, Heinzow HS. Testosterone treatment for patients with sarcopenia and liver cirrhosis. Z Gastroenterol 2017;55:594-595.

83. Becker C, Lord SR, Studenski SA, Warden SJ, Fielding RA, Recknor CP, et al. Myostatin antibody (LY2495655) in older weak fallers: a proof-of-concept, randomized, phase 2 trial. Lancet Diabetes Endocrinol 2015;3:948-957.

84. Han HQ, Zhou X, Mitch WE, Goldberg AL. Myostatin/activin pathway antagonism: molecular basis and therapeutic potential. Int J Biochem Cell Biol 2013;45:2333-2347.

85. Picardi A, de Oliveira AC, Muguerza B, Tosar A, Quiroga J, CastillaCortázar I, et al. Low doses of insulin-like growth factor-I improve nitrogen retention and food efficiency in rats with early cirrhosis. J Hepatol 1997;26:191-202.

86. Nardelli S, Lattanzi B, Torrisi S, Greco F, Farcomeni A, Gioia S, et al. Sarcopenia is risk factor for development of hepatic encephalopathy after transjugular intrahepatic portosystemic shunt placement. Clin Gastroenterol Hepatol 2017;15:934-936.

87. Semsarian C, Wu MJ, Ju YK, Marciniec T, Yeoh T, Allen DG, et al. Skeletal muscle hypertrophy is mediated by a Ca2+-dependent calcineurin signaling pathway. Nature 1999;400:576-581.

88. Bergerson JT, Lee JG, Furlan A, Sourianarayanane A, Fetzer DT, Tevar $A D$, et al. Liver transplantation arrests and reverses muscle wasting. Clin Transplant 2015;29:216-221. 